\title{
НЕОБХОДИМОСТЬ И БЕЗОПАСНОСТЬ ПРИМЕНЕНИЯ ФАВИПИРАВИРА В \\ ЛЕЧЕНИИ ВЗРОСЛЫХ ПАЦИЕНТОВ С COVID-19 \\ Руженцова Т.А. ${ }^{1}$ Чухляев П.В. ${ }^{1}$, Хавкина Д.А. ${ }^{1}$, Гарбузов А.А. ${ }^{1}$, Никольская М.В. ${ }^{2}$, Разживина В.А. ${ }^{2}$, Филон О.В. ${ }^{2}$ \\ ${ }^{1}$ ФБУН ЦНИИ Эпидемиологии Роспотребнадзора, г. Москва \\ ${ }^{2} \mathrm{OOO}$ «Технология лекарств», Химки, Россия
}

\section{Резюме}

В статье представлены результаты исследования безопасности и необходимости применения препарата фавипиравира в лечении пациентов с нетяжелыми формами COVID19, по сравнению с другой этиотропной терапией (умифеновир, гироксихлорохин).

Цель исследования - обосновать необходимость и безопасность применения фавипиравира в терапии нетяжелых форм COVID-19 у взрослых пациентов.

\section{Материалы и методы}

В исследование было включено 168 пациентов. Из них 108 получали в качестве этиотропной терапии препарат фавипиравир (основная группа), а 55 (группа сравнения) умифеновир и/или гидроксихлорохин.

В качестве основных точек исследования сравнивали быстроту клинического улучшения по шкале ВОЗ и срок элиминации вируса, наличие или отсутствие нежелательных явлений, вызванных непосредственно принимаемыми препаратами, а также их выраженность.

\section{Результаты}

В обеих группах были зарегистрированы нежелательные явления. Наиболее часто среди всех пациентов в обеих группах отмечали кратковременное повышение печеночных трансаминаз. В основной группе более частым нежелательным явлением была гиперурекимия, что является ожидаемой реакцией и корректируется с отменой препарата без отдаленных последствий. При этом в основной группе зафиксирована более быстрая элиминация вируса: на 3-й день - у 71,4\% пациентов в группе фавипиравира и у 57,1\% в группе стандартной терапии, а на 5-й день: у 81,2\% и 67,9\%, соответственно. Клиническое улучшение в основной группе наступало на 4 дня раньше, чем в группе сравнения (p =0,005).

\section{Выводы}


1. Применение этиотропной терапии при лечении COVID-19 на ранних этапах и при нетяжелых формах заболевания оправдано, необходимо и способствует снижению риска перехода инфекции в хроническую форму.

2. Выбор фавипиравира в качестве стартового препарата обоснован достаточно ранней элиминацией вируса SARS-CoV-2 и значительно более ранним наступлением клинического улучшения по шкале ВОЗ - на 4 дня раньше, чем при приёме умифеновира или гидроксихлорохина.

3. При оценке профиля безопасности фавипиравира серьезных нежелательных явлений отмечено не было. Однако при его назначении следует помнить о том, что он противопоказан к применению у беременных женщин в связи с тератогенным влиянием на плод. Кроме того, его применение требует дополнительной контрацепции при приеме препарата, как мужчинам, так и женщинам на всем протяжении приема и в течение трех месяцев после.

Ключевые слова: SARS-CoV-2, вирусная инфекция, фавипиравир, гидроксихлорохин, умифеновир, ОРВИ, печеночные трансаминазы, гиперурекемия.

\author{
NECESSITY AND SAFETY OF ETIOTROPIC THERAPY IN THE TREATMENT OF \\ ADULT PATIENTS WITH COVID-19 \\ T.A. Ruzhentsova, D. A. Khavkina, P.V. Chuchliaev, A.A. Garbuzov \\ Central Research Institute of Epidemiology, Moscow, Russia
}

\begin{abstract}
The article presents results of the safety and necessity of using favipiravir in the treatment of patients with mild forms of COVID-19, compared with another therapy (umifenovir, giroxychloroquine).

\section{Materials and methods}

The main points of the study compared the speed of clinical improvement on the WHO scale and the speed of virus elimination, the presence or absence of adverse events caused by directly taken drugs, as well as their severity. A total of 168 patients were included in the study. Of these, 108 patients received favipiravir as etiotropic therapy, while 55 patients in the comparison group received umifenovir and / or hydroxychloroquine.
\end{abstract}

\title{
Results
}


In both groups, adverse events were reported in the form of a short-term increase in hepatic transaminases. In the main group, hyperurekemia was a more frequent adverse event, which is an expected reaction and is corrected with the drug withdrawal without long-term consequences. The main group showed faster virus elimination and clinical improvement than the comparison group (on average, for 4 days $(\mathrm{p}=0.005)$ ).

\section{Conclusions}

1. The use of etiotropic therapy in the treatment of COVID-19 at early stages and in nonsevere forms of the disease is justified, necessary and helps reduce the risk of infection becoming chronic.

2. The choice of favipiravir as the starting drug is justified by the early elimination of the SARS-CoV-2 virus and significantly earlier onset of clinical improvement on the who scale-4 days earlier than when taking umifenovir or hydroxychloroquine.

3. When assessing the safety profile of favipiravir serious adverse events were noted. However, when prescribing it, it should be remembered that it is contraindicated for use in pregnant women due to the teratogenic effect on the fetus. In addition, its use requires additional contraception when taking the drug, both for men and women throughout the course of taking it and for three months after.

Key words: SARS-CoV-2, viral infection, favipiravir, hydroxychloroquine, umifenovir, SARS-CoV-2, hepatic transaminases, hyperurikemia.

\section{Введение}

В настоящее время методики лечения COVID-19 различаются не только в общемировом масштабе, но и в рамках субъектов, а иногда и отдельных учреждений конкретных муниципальных образований России. Несмотря на накопленный опыт весенней волны пандемии, противоречия в тактике диагностики и лечения инфекции, вызванной SARS-CoV-2, не стали менее значимыми. Один из наиболее острых вопросов заключается в том, как оптимизировать лечение пациентов с нетяжелыми формами COVID-19, какую этиотропную терапию назначить, чтобы она и эффективной, и безопасной.

Так, несмотря на достаточно высокую эффективность, значительную кардиотоксичность демонстрируют препараты гидроксихлорохина [1]. Тем не менее, на сегодняшний день золотым стандартом терапии вирусной инфекции является своевременное (с первых дней болезни) включение этиотропных лекарственных средств. Раннее назначение противовирусных препаратов способствует более быстрой элиминации вируса и 
предупреждает возникновение хронических очагов вирусной инфекции и развитие, порой фатальных осложнений в более поздние периоды заболевания, обусловленных ошибочной тактикой ведения больного, а именно - отказом лечащего врача от назначения противовирусной терапии или ее несвоевременным введением в протокол лечения [2]. На сегодняшний день доказан тот факт, что медленные (хронические вирусные инфекции) способствуют поражению жизненно-важных органов, вызывая латентно протекающие и труднодиагностируемые миокардиты, энцефалиты, васкулиты и другие повреждения органов и систем $[3,4]$.

В то же время избыточное назначение лекарственных средств также способно привести к неблагоприятному течению болезни за счет медикаментозно опосредованного влияния на организм, например, сочетанное применение гидроксихлорохина с азитромицином [5].

В статье представлены результаты безопасности и необходимости применения препарата фавипиравира в лечении пациентов с нетяжелыми формами COVID-19, по сравнению со стандартной терапией (умифеновир, гироксихлорохин). В качестве основных точек исследования сравнивали быстроту клинического улучшения по шкале ВОЗ и частоту элиминации вируса, наличие или отсутствие нежелательных явлений, вызванных непосредственно принимаемыми препаратами, а также их выраженность.

Цель исследования - обосновать необходимость и безопасность применения фавипиравира в терапии нетяжелых форм COVID-19 у взрослых пациентов.

\section{Материалы и методы}

В исследование было включено 168 пациентов. Все пациенты подписали информированное согласие на участия в исследовании. Рандомизация производилась в соотношении 2:1 в группу исследуемой терапии и группу сравнения, соответственно. Включение в исследование проводилось по следующим критериям: легкая и среднетяжелая степень тяжести заболевания, возраст от 18 до 65 лет, выраженность патологии на КТ органов грудной клетки (КТ-0 - KT-1 и КТ-2 - KТ-3). Пациенты, включенные в основную группу, на протяжении 10 дней получали терапию препаратом «Коронавир» (фавипиравир) перорально: в первый день нагрузочную дозу - по 1800 мг с интервалом в 12 часов (т.е. 2 раза в сутки), далее в дни 2-10 по 800 мг с интервалом в 12 часов (т.е. 2 раза в сутки). Пациенты в группе сравнения получали рекомендованную «стандартную» этиотропную терапию в соответствии с актуальной версией Временных методических рекомендаций Минздрава России «Профилактика, диагностика и лечение коронавирусной инфекции (COVID-19)», 
действовавшей на момент проведения исследования (версия 6) [6]. В группе сравнения пациенты, по решению лечащего врача, могли получать умифеновир в комбинации с интерфероном-альфа, либо хлорохин или его производные (хлорохин/гидроксихлорохин или мефлохин) с использованием стандартных схем. В качестве сопутствующей терапии пациентам обеих групп при необходимости назначали жаропонижающие препараты; мукоактивные, бронхолитические и прочие средства; антикоагулянты, антибактериальную терапию при присоединении вторичной инфекции.

Для оценки эффективности терапии у всех пациентов на производилась оценка клинического статуса, наличия тех или иных симптомов, забор биоматериала (мазок) из верхних дыхательных путей (из зева и носа) для определения наличия вируса SARS-CoV-2 методом ПЦР. Всем пациентам измеряли температуру тела, артериальное давление (АД), частоту сердечных сокращений (ЧСС) и частоту дыхательных движений (ЧДД), насыщение крови кислородом (по данным пульсоксиметрии, $\mathrm{SpO}_{2}$ ), ЭКГ и компьютерную томографию (КТ) органов грудной клетки.

Оценка лабораторных показателей производилась на скрининге, далее в дни 5, 14 и 28. Выполняли клинический анализ крови (определение гемоглобина, числа эритроцитов, лейкоцитов, нейтрофилов, лимфоцитов, тромбоцитов, СОЭ); биохимический анализ крови (с определением уровней глюкозы, аланинаминотрансферазы аспартатаминотрансферазы (АСТ), лактатдегидрогеназы (ЛДГ), билирубина общего, креатинина, креатинфосфокиназы (КФК), ферритина, лактата, мочевой кислоты); Среактивного белка; коагулограмму (активированное частичное тромбопластиновое время (АЧТВ), протромбиновое время, фибриноген, D-димер); общий анализ мочи.

Оценка безопасности включала сбор данных о жалобах, клиническом статусе и результатах лабораторных анализов.

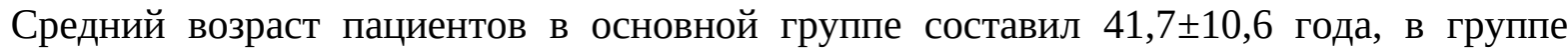

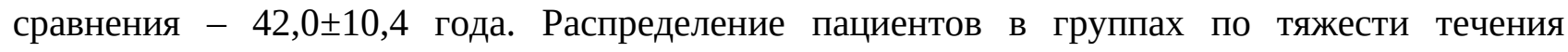
заболевания было равноценным: легкое течение - у 25,0\% в основной группе и 26,8\% в группе сравнения, среднетяжелое - у 75,0\% и 73,2\%, соответственно.

Пациенты группы сравнения получали рекомендованную «стандартную» этиотропную терапию: умифеновир, капсулы 200 мг, применяли по 1 капсуле 4 раза в сутки перорально в течение 5 дней; рекомбинантный интерферон альфа-2b, капли назальные 10000 ME/мл, по 3 капли в каждый носовой ход 5 раз в день в течение 5 дней. При наличии признаков продолжения заболевания курс пролонгировали до 10 дней. Гидроксихлорохин применяли с 
использованием следующих схем: схема 1: 800 мг в первый день (400 мг 2 р/сут), далее 400 мг в сутки (200 мг 2 р/сут), в течение 6-8 дней (применение в условиях стационара при наличии возможности мониторинга интервала QT), или схема 2: 400 мг в первый день (200 мг 2 р/сут), далее 200 мг в сутки (100 мг 2 р/сут), в течение 6-8 дней (применение в амбулаторной практике или при отсутствии возможности мониторинга интервала QT).

Эффективность фавипиравира оценивалась на основании данных определения времени до улучшения клинического статуса и времени до достижения элиминации вируса (отсутствие SARS-CoV-2 по результатам 2-х последовательных ПЦР мазков с интервалом не менее 24 часов).

Статистический анализ проводили с помощью t-критерия Стьюдента, U-критерия Манна-Уитни, Т-критерия Вилкоксона, параметрического дисперсионного анализа (ANOVA) для повторных измерений, критерия Фридмана и критерия Фишера.

\section{Результаты и обсуждение}

Наиболее значимый результат для пациентов заключался в достижении клинического улучшения до полного выздоровления или неярко выраженных симптомов без ограничений повседневной активности по порядковой шкале клинического улучшения ВОЗ через, в среднем, 6,0 дней в основной группе и через 10,0 дней в группе сравнения. Разница составила 4 дня, что существенно для больных COVID-19 и является статистически достоверным (p = 0,005).

Частота элиминации вируса в основной группе была значимо выше уже на 3-й день лечения: у 71,4\% пациентов в группе, получавшей фавипиравир и у 57,1\% в группе, получавшей стандартную терапию. На 5-й день вирус не обнаруживался у 81,2\% пациентов в основной группе и у 67,9\% в группе сравнения. В ходе исследования какие-либо нежелательные явления были зарегистрированы у большей части пациентов в обеих группах: у 74,1\% (80 из 108) пациентов в основной группе и у 60,0\% (33 из 55) пациентов в группе сравнения. Несмотря на зарегистрированную разницу, она не была статистически значимой $(\mathrm{p}=0,074)$. По отдельным показателям статистически значимая разница была только по частоте гиперурикемии в основной группе: у 41,7\% по сравнению с 3,6\% (p = 0,001), что является ожидаемым для действия фавипиравира на основании данных литературы [7]. Большинство нежелательных явлений имели легкую степень выраженности. В общей сложности при проведении этого исследования было зарегистрировано 12 тяжелых нежелательных явлений без достоверных различий между группами. В основной группе были выделены следующие: повышение АЛТ и АСТ одновременно у 1 пациента, 1 случай 
изолированного повышения АСТ и 2 случая повышения АЛТ. В группе сравнения было зарегистрировано 4 нежелательных явления 3 степени у 3 пациентов: повышение уровня КФК у 1 пациента, изолированное повышение АЛТ у 1 пациента и одновременное повышение уровня АСТ и АЛТ у 1 пациента. Во всех случаях значимого повышения АСТ и/или АЛТ пациенты, помимо фавипиравира, получали значительное количество препаратов сопутствующей терапии, которые в подавляющем большинстве случаев способны привести к повышению уровня печеночных трансаминаз (азитромицин, левофлоксацин, амоксициллина клавуланат, цефтриаксон, ибупрофен).

Отмена исследуемого препарата в связи с нежелательными явлениями потребовалась 3-м пациентам: 2-м в основной группе (в связи с повышением АЛТ и АСТ 3 степени и повышением АЛТ и АСТ 2 степени) и 1-му пациенту в группе сравнения (пациент получал гидроксихлорохин) в связи с повышением АЛТ 3 степени. После отмены терапии нежелательные явления у обоих пациентов разрешились без негативных последствий. Случаев досрочного выбывания пациентов из исследования по причине нежелательных явлений не наблюдалось. Случаев смерти в исследовании также не зарегистрировано (таблица 1).

Таблица 1. Анализ основных показателей безопасности по данным, доступным на момент проведения промежуточного анализа.

\begin{tabular}{|c|c|c|c|}
\hline Показатель & $\begin{array}{c}\text { Основная группа } \\
(\mathrm{N}=108)\end{array}$ & $\begin{array}{c}\text { Группа сравнения } \\
(\mathrm{N}=55) \\
\end{array}$ & Значение р \\
\hline $\begin{array}{l}\text { Любые } \\
\text { нежелательные } \\
\text { явления }\end{array}$ & $80(74,1 \%)$ & $33(60,0 \%)$ & $0,074^{1}$ \\
\hline $\begin{array}{l}\text { Нежелательные } \\
\text { явления 3-4 ст. }\end{array}$ & $8(7,4 \%)$ & $4(7,3 \%)$ & $1,000^{1}$ \\
\hline $\begin{array}{l}\text { Нежелательные } \\
\text { реакции }\end{array}$ & $70(63,9 \%)$ & $32(58,2 \%)$ & $0,309^{1}$ \\
\hline $\begin{array}{l}\text { Нежелательные } \\
\text { реакции 3-4 ст. }\end{array}$ & $4(3,7 \%)$ & $3(5,5 \%)$ & $0,689^{1}$ \\
\hline $\begin{array}{l}\text { Серьезные } \\
\text { нежелательные } \\
\text { явления }\end{array}$ & $2(1,9 \%)^{*}$ & $0(0,0 \%)$ & $0,550^{1}$ \\
\hline $\begin{array}{l}\text { Отмена препарата по } \\
\text { причине } \\
\text { нежелательных } \\
\text { явлений }\end{array}$ & $2(1,9 \%)$ & $1(1,8 \%)$ & $1,000^{1}$ \\
\hline
\end{tabular}


Спектр зарегистрированных нежелательных явлений, в целом, соответствует описанному в литературе профилю безопасности фавипиравира [8]. В основной группе большинство зарегистрированных нежелательных явлений представляли собой симптомы со стороны ЖКТ (более 5\% пациентов): диарея, тошнота, боль в животе, боль в верхних отделах живота. Среди лабораторных отклонений с высокой частотой (более 10\%) в основной группе регистрировали гиперурикемию, повышение уровня АЛТ, повышение уровня АСТ, повышение КФК, гипергликемия (таблица 2).

Таблица 2. Наиболее значимые НР, выявленные при анализе, по классам систем органов.

\begin{tabular}{|c|c|c|c|}
\hline $\begin{array}{c}\text { Нежелательные } \\
\text { реакции }\end{array}$ & $\begin{array}{c}\text { Основная } \\
\text { группа } \\
\text { (N = 108) }\end{array}$ & Группа сравнения (N = 55) & Значение $\mathbf{p}^{1}$ \\
\hline \multicolumn{4}{|c|}{ Нарушения метаболизма и питания } \\
\hline Гиперурикемия & $43(39,8 \%)$ & $2(3,6 \%)$ & $\mathbf{0 , 0 0 0 *}$ \\
\hline Гипергликемия & $11(10,2 \%)$ & $6(10,9 \%)$ & 1,000 \\
\hline \multicolumn{4}{|c|}{ Нарушения со стороны печени и желчевыводящих путей } \\
\hline $\begin{array}{l}\text { Повышение уровня } \\
\text { АЛТ }\end{array}$ & $36(33,3 \%)$ & $11(20,0 \%)$ & 0,099 \\
\hline 1 ст. & $29(26,7 \%)$ & $7(12,7 \%)$ & 0,046* \\
\hline 2 ст. & $4(3,7 \%)$ & $2(3,6 \%)$ & 1,000 \\
\hline З ст. & $3(2,8 \%)$ & $2(3,6 \%)$ & 1,000 \\
\hline $\begin{array}{l}\text { Повышение уровня } \\
\text { АСТ }\end{array}$ & $24(22,2 \%)$ & $5(9,1 \%)$ & 0,050 \\
\hline 1 ст. & $19(17,6 \%)$ & $3(5,5 \%)$ & 0,057 \\
\hline 2 ст. & $3(2,8 \%)$ & $1(1,8 \%)$ & 1,000 \\
\hline 3 ст. & $2(1,9 \%)$ & $1(1,8 \%)$ & 1,000 \\
\hline Гипербилирубинемия & $4(3,7 \%)$ & $5(9,1 \%)$ & 0,275 \\
\hline $\begin{array}{l}\text { Повышение уровня } \\
\text { ЛДГ в крови }\end{array}$ & $6(5,6 \%)$ & $1(1,8 \%)$ & 0,425 \\
\hline 1 ст. & $5(4,6 \%)$ & $1(1,8 \%)$ & 0,439 \\
\hline 2 ст. & $1(0,9 \%)$ & $0(0,0 \%)$ & 1,000 \\
\hline \multicolumn{4}{|c|}{ Желудочно-кишечные нарушения } \\
\hline $\begin{array}{l}\text { Абдоминальный } \\
\text { дискомфорт }\end{array}$ & $0(0,0 \%)$ & $1(1,8 \%)$ & 0,337 \\
\hline Диарея & $16(14,8 \%)$ & $7(12,7 \%)$ & 0,815 \\
\hline 1 ст. & $15(13,9 \%)$ & $7(12,7 \%)$ & 1,000 \\
\hline 2 ст. & $1(0,9 \%)$ & $0(0,0 \%)$ & 1,000 \\
\hline Тошнота & $9(8,3 \%)$ & $5(9,1 \%)$ & 1,000 \\
\hline 1 ст. & $9(8,3 \%)$ & $4(7,3 \%)$ & 1,000 \\
\hline 2 ст. & $0(0,0 \%)$ & $1(1,8 \%)$ & 0,337 \\
\hline Рвота & $1(0,9 \%)$ & $1(1,8 \%)$ & 1,000 \\
\hline $\begin{array}{l}\text { Боль в верхних } \\
\text { отделах живота }\end{array}$ & $7(6,5 \%)$ & $1(1,8 \%)$ & 0,268 \\
\hline Боль в животе & $8(7,4 \%)$ & $4(7,3 \%)$ & 1,000 \\
\hline \multicolumn{4}{|c|}{ Лабораторные и инструментальные данные } \\
\hline $\begin{array}{l}\text { Повышение уровня } \\
\text { КФК в крови }\end{array}$ & $15(13,8 \%)$ & $11(20,0 \%)$ & 0,367 \\
\hline 1 ст. & $14(13,0 \%)$ & $10(18,2 \%)$ & 0,483 \\
\hline 2 ст. & $1(0,9 \%)$ & $0(0,0 \%)$ & 1,000 \\
\hline 3 ст. & $0(0,0 \%)$ & $1(1,8 \%)$ & 0,337 \\
\hline
\end{tabular}




\begin{tabular}{|c|c|c|c|}
\hline $\begin{array}{c}\text { Нежелательные } \\
\text { реакции }\end{array}$ & $\begin{array}{c}\text { Основная } \\
\text { группа } \\
\text { (N = 108) }\end{array}$ & Группа сравнения (N = 55) & Значение $\mathbf{p}^{1}$ \\
\hline \multicolumn{4}{|c|}{ Нарушения со стороны сердца } \\
\hline $\begin{array}{l}\text { Синусовая } \\
\text { брадикардия }\end{array}$ & $10(9,3 \%)$ & $2(3,6 \%)$ & 0,227 \\
\hline Синусовая тахикардия & $3(2,8 \%)$ & $2(3,6 \%)$ & 1,000 \\
\hline \multicolumn{4}{|c|}{ Нарушения со стороны кожи и подкожной клетчатки } \\
\hline Сыпь & $4(3,7 \%)$ & $0(0,0 \%)$ & 0,301 \\
\hline \multicolumn{4}{|c|}{ Нарушения со стороны почек и мочевыводящих путей } \\
\hline Гематурия & $2(1,9 \%)$ & $0(0,0 \%)$ & 0,550 \\
\hline Гиперкреатининемия & $1(0,9 \%)$ & $2(3,6 \%)$ & 0,263 \\
\hline \multicolumn{4}{|c|}{ Нарушения со стороны нервной системы } \\
\hline Головная боль & $4(3,7 \%)$ & $1(1,8 \%)$ & 0,664 \\
\hline \multicolumn{4}{|c|}{ Нарушения со стороны мышечной, скелетной и соединительной ткани } \\
\hline Мышечная слабость & $1(0,9 \%)$ & $0(0,0 \%)$ & 1,000 \\
\hline
\end{tabular}

Таким образом, назначение этиотропной терапии необходимо при COVID-19, как и при любой другой вирусной инфекции. Это обеспечивает более ранний выход из болезни и способствует снижению количества осложнений в период реконвалесценции.

В то же время изменение биохимического профиля крови возможно не только и не столько от применения противовирусных средств, сколько от сочетанной терапии, включая прием нестероидных противовоспалительных препаратов, антибактериальных лекарственных средств и иной сопутствующей медикаментозной коррекции, чье влияние на существенное изменение лабораторных показателей доказано и общеизвестно.

\section{Выводы}

1. Применение этиотропной терапии при лечении COVID-19 на ранних этапах и при нетяжелых формах заболевания оправдано, необходимо и способствует снижению риска перехода инфекции в хроническую форму.

2. Выбор фавипиравира в качестве стартового препарата обоснован достаточно ранней элиминацией вируса SARS-CoV-2 и значительно более ранним наступлением клинического улучшения по шкале ВОЗ - на 4 дня раньше, чем при приёме умифеновира или гидроксихлорохина.

3. При оценке профиля безопасности фавипиравира серьезных нежелательных явлений отмечено не было. Однако при его назначении следует помнить о том, что он противопоказан к применению у беременных женщин в связи с тератогенным влиянием на плод. Кроме того, его применение требует дополнительной контрацепции при приеме препарата, как мужчинам, так и женщинам на всем протяжении приема и в течение трех месяцев после. 


\section{Сведения об авторах}

Руженцова Татьяна Александровна - доктор медицинских наук, руководитель отдела клинических исследований, профессор образовательного центра Федерального бюджетного учреждения науки «Центральный научно-исследовательский институт эпидемиологии» Федеральной службы по надзору в сфере защиты прав потребителей и благополучия человека; 111123, г. Москва, ул. Новогиреевская, д. ЗА; тел. +7-495-304-56-96; e-mail: ruzhencova@gmail.com; ORCID: 0000-0002-6945-2019.

Хавкина Дарья Александровна - ведущий специалист отдела клинических исследований Федерального бюджетного учреждения науки «Центральный научноисследовательский институт эпидемиологии» Федеральной службы по надзору в сфере защиты прав потребителей и благополучия человека; 111123, г. Москва, ул. Новогиреевская, д. 3А; тел. +7-495-304-56-96; e-mail: havkina@gmail.com; ORCID: 0000-0001-5919-9841.

Чухляев Павел Владимирович - ведущий специалист отдела клинических исследований Федерального бюджетного учреждения науки «Центральный научноисследовательский институт эпидемиологии» Федеральной службы по надзору в сфере защиты прав потребителей и благополучия человека; 111123, г. Москва, ул. Новогиреевская, д. 3А; тел. +7-495-304-56-96; e-mail: pafachka@gmail.com, ORCID:0000-0003-1210-1215.

Гарбузов Александр Александрович - методист отдела клинических исследований Федерального бюджетного учреждения науки «Центральный научно-исследовательский институт эпидемиологии» Федеральной службы по надзору в сфере защиты прав потребителей и благополучия человека; 111123, г. Москва, ул. Новогиреевская, д. ЗА; тел. +7495-304-56-96; e-mail: os.vertebra@mail.ru, ORCID: 0000-0002-3378-8418.

Никольская Мария Викторовна - руководитель отдела медицинской информации ООО «Технология лекарств», Химки, Россия; e-mail: nikolskaja.m@gmail.com

Разживина Виктория Александровна - к.б.н., руководитель отдела клинических исследований ООО «Технология лекарств», Химки, Россия; e-mail: var@drugsformulation.ru

Филон Ольга Владимировна - медицинский директор ООО «Технология лекарств», Химки, Россия; e-mail: Filon@drugsformulation.ru

\section{For correspondence:}

Tatiana A. Ruzhentsova, Doctor of medical sciences, Head of clinical research Department, professor of Educational Center of Central Research Institute of Epidemiology, Russian Federal 
Supervision Service for Consumer Rights Protection and People's Welfare; Address: 3a, Novogireevskaya St., Moscow 111123, Russia; Telephone: +7(495) 672-11-58; e-mail: ruzhencova@gmail.com; ORCID: 0000-0002-6945-2019.

Daria A. Khavkina, Leading specialist, Clinical research Department of Central Research Institute of Epidemiology, Russian Federal Supervision Service for Consumer Rights Protection and People’s Welfare; Address: 3a, Novogireevskaya St., Moscow 111123, Russia; Telephone: +7-495672-11-58; e-mail: havkina@gmail.com; ORCID: 0000-0001-5919-9841.

Pavel V. Chukhliaev, Leading specialist, Clinical research Department of Central Research Institute of Epidemiology, Russian Federal Supervision Service for Consumer Rights Protection and People’s Welfare; Address: 3a, Novogireevskaya St., Moscow 111123, Russia; Telephone: +7-495672-11-58; e-mail: pafachka@gmail.com, ORCID:0000-0003-1210-1215.

Alexander A. Garbuzov - Methodist of clinical research Department of Central Research Institute of Epidemiology, Russian Federal Supervision Service for Consumer Rights Protection and People’s Welfare; Address: 3a, Novogireevskaya St., Moscow 111123, Russia; Telephone: +7-495672-11-58; e-mail: os.vertebra@mail.ru.

Maria V. Nikolskaya, Head, Medical information Department, LLC «Technology of drugs», Khimki, Russia; e-mail: nikolskaja.m@gmail.com

Victoria A. Razzhivina, PhD, Head, Clinical Research Department, LLC «Technology of drugs», Khimki, Russia; e-mail: var@drugsformulation.ru

Olga V. Filon, Medical Director, «Technology of drugs», Khimki, Russia; e-mail: Filon@drugsformulation.ru

Конфликт интересов:

Авторы заявляют об отсутствии конфликта интересов

\section{Conflict of interests}

The authors claim that there is no conflict of interest.

\section{Список литературы}


1. Colson P., Rolain J.M., Lagier J.C., Brouqui P, Raoult D. Chloroquine and hydroxychloroquine as available weapons to fight COVID-19. Int. J. Antimicrob. Agents 2020; 55(4): 105932. doi: 10.1016/j.ijantimicag.2020. 105932.

2. Руженцова Т.А., Хавкина Д.А., Чухляев П.В., Мешкова Н.А., Гарбузов А.А. Стратегия рациональной терапии острых респираторных инфекций у пациентов с коморбидной соматической патологией. Безопасность и риск фармакотерапии. 2020: 2(8); 77 83. doi.org/10.30895/2312-7821-2020-8-2-77-83.

3. Руженцова Т.А., Горелов А.В. Значение острых респираторных вирусных инфекций в развитии хронической патологии сердца у детей. Эпидемиология и инфекционные болезни: актуальные вопросы. 2012: 3; 42-46.

4. Руженцова Т.А., Плоскирева А.А., Щербаков И.Т., Исаева Е.И., Бондарева А.В., Горелов А.В. Поражения миокарда при Коксаки А вирусной инфекции. Фундаментальные исследования. 2015: 1(5); 1033-1037.

5. Gautret Ph., Gautret P., Lagier J.C., Parola P. et al. Hydroxychloroquine and azithromycin as a treatment of COVID-19: results of an open-label non-randomized clinical trial. Int. J. Antimicrob. Agents 2020: 105949. DOI:10.1016/j.ijantimicag.2020.105949.

6. Профилактика, диагностика и лечение новой коронавирусной инфекции (Covid-19). Временные методические рекомендации Минздрава России. Версия 6 (28.04.2020). https://static1.rosminzdrav.ru/system/attachments/attaches/000/050/122/original/ 28042020_MR_COVID-19_v6.pdf. [Prevention, diagnosis and treatment of new coronavirus infection (Covid-19). Temporary guidelines, Ministry of Health of Russia. Version 6 (28.04.2020)]. https: //static1.rosminzdrav.ru/system/attachments/attaches/000/050/122/original/ 28042020_MR_COVID-19_v6.pdf.

7. Руженцова Т. А., Чухляев П. В., Хавкина Д. А., Гарбузов А. А., Осешнюк Р. А., Солуянова Т. Н., Шестакова И. В., Вафин А. Ю., Дмитрикова Е. П., Мустафаев Д. , Домостроева Т. Н., Отпущенникова М. В., Покровский К. А., Русанова М. Г., Быстрицкий Д. А., Маркова Т. Н., Каплун Е. А., Петина Д. В., Костина Н. Э., Лесина В. С., Щербак С. Г., Агафьина А. С., Брук Ю. Ф., Бронов О. Ю., Шульц Е. И., Красавина Э. Н., Самсонов М. Ю., Зинченко А. В., Никольская М. В., Разживина В. А., Филон О. В. 2020. Эффективность и безопасность применения фавипиравира при COVID-19 легкого и среднетяжелого течения: результаты рандомизированного исследования. COVID19-PREPRINTS.MICROBE.RU. https:// doi.org/10.21055/preprints-3111892. 
8. Руженцова Т.А., Чухляев П.В., Хавкина Д.А., Гарбузов А.А., Плоскирева А.А., Осешнюк Р.А., Солуянова Т.Н., Шестакова И.В., Вафин А.Ю., Дмитрикова Е.П., Мустафаев Д.М., Домостроева Т.Н., Красавина Э.Н., Самсонов М.Ю., Никольская М.В., Разживина В.А., Филон О.В. Возможности этиотропной терапии коронавирусной инфекции, вызванной SARSCoV-2, у амбулаторных пациентов. Медицинский оппонент. 2020: 1; 48-58. http://proffopponent.ru/2020/08/05/vozmozhnosti-jetiotropnoj-terapii-koronavirusnoj-infekciivyzvannoj-sars-cov-2-u-ambulatornyh-pacientov/. 